\title{
NILAI TAMBAH SABUT KELAPA PADA INDUSTRI PENGOLAHAN PT. BERKAT ABADI KORINDO KECAMATAN MATUARI KOTA BITUNG
}

\section{ADDED VALUE OF COCONUT COIR IN THE PROCESSING INDUSTRY OF PT. BERKAT ABADI KORINDO MATUARI SUB-DISTRICT BITUNG CITY}

\author{
Aldi Dian Sahputra Menang. ${ }^{(1)}$, Nordy Fritsgerald Lucky Waney ${ }^{(2)}$, Mex Frans Lodwyk Sondakh ${ }^{(2)}$ \\ 1) Mahasiswa Program Studi Agribisnis, Fakultas Pertanian, Universitas Sam Ratulangi, Manado \\ 2) Dosen Program Studi Agribisnis, Fakultas Pertanian, Universitas Sam Ratulangi, Manado \\ *Penulis untuk korespondensi: menangaldi0@gmail.com
}

Naskah diterima melalui Website Jurnal Ilmiah agrisosioekonomi@unsrat.ac.id

Jumat, 26 Februari 2021

Disetujui diterbitkan

Jumat, 28 Mei 2021

\begin{abstract}
This study aims to determine the added value of coconut coir in the processing industry of PT. Berkat Abadi Korindo, Bitung City. This research was conducted at PT Berkat Abadi Korindo Bitung City from January to March 2020. The location was determined purposively with the consideration that PT. Berkat Abadi Korindo is the only company that processes coconut coir into "Fish Net" products in North Sulawesi. The type of data used in this study is primary data obtained through direct interviews with company owners using a list of data requirements that have been prepared as well as direct observations about conditions in the field during the analysis period. The research data were analyzed descriptively and quantitatively using added value analysis. The results of this study indicate the coconut coir processing industry of PT. Berkat Abadi Korindo, Matuari Sub-District, Bitung City provides added value of more than 0 or Rp. 2,331.14 from every $1 \mathrm{~kg}$ of coconut husk to $0.16 \mathrm{~kg}$ of "Fish Net".
\end{abstract}

Keywords: Added Value; Processing Industry

ABSTRAK

Penelitian ini bertujuan Untuk mengetahui Nilai Tambah sabut kelapa pada industri pengolahan PT. Berkat Abadi Korindo Kota Bitung. Penelitian ini dilaksanakan di PT Berkat Abadi Korindo Kota Bitung pada bulan Januari hingga Maret 2020. Penentuan lokasi dilakukan secara sengaja (purposive) dengan pertimbangan bahwa PT. Berkat Abadi Korindo merupakan satu-satunya perusahaan yang mengolah sabut kelapa menjadi produk "Fish Net" yang ada di Sulawesi Utara. Jenis data yang digunakan dalam penelitian ini adalah data primer yang diperoleh melalui wawancara secara langsung dengan pemilik perusahaan menggunakan list kebutuhan data yang telah dipersiapkan serta pengamatan langsung tentang keadaan di lapangan selama periode analisis. Data hasil penelitian di analisis secara deskriptif kuantitatif menggunakan analisis nilai tambah. Hasil penelitian ini menunjukkan industri pengolahan sabut kelapa PT. Berkat Abadi Korindo Kecamatan Matuari Kota Bitung memberikan nilai tambah lebih dari 0 atau sebesar Rp 2.331,14 dari setiap $1 \mathrm{~kg}$ sabut kelapa menjadi $0,16 \mathrm{~kg}$ "Fish Net".

Kata kunci: Nilai Tambah; Industri Pengolahan 


\section{PENDAHULUAN}

\section{Latar Belakang}

Indonesia merupakan produsen kelapa terluas di dunia, menurut statistik perkebunan Indonesia pada tahun 2017 oleh Dirjen Perkebunan menunjukan bahwa luas perkebunan tanaman kelapa mencapai 3.544.393 Ha dan total produksi sebanyak 2.871.280 Ton, yang menjadikan produk kelapa dan turunannya di Indonesia memiliki potensi untuk di kembangkan karena memliki nilai yang sangat strategis.

Daya saing produk kelapa saat ini terletak pada industry hilir, Nilai produk kelapa dapat tercipta berlipat ganda pada produk hilir dari pada produk primernya, produk turunan kelapa di ekspor dalam berbagai bentuk seperti tepung kelapa, minyak kelapa, copra, karbon aktif, arang tempurung dan sabut kelapa. Data ekspor menunjukan sabut kelapa dan turunannya memiliki peningkatan ekspor setiap tahunnya dapat dilihat pada Tabel 1 .

Tabel 1. Data ekspor sabut kelapa Indonesia tahun 2015 hingga 2018

\begin{tabular}{lcc}
\hline \multirow{2}{*}{ Tahun } & \multicolumn{2}{c}{ Komoditi sabut kelapa } \\
\cline { 2 - 3 } & Volume (Ton) & Nilai (000US\$) \\
\hline 2015 & 17.728 & 11.911 \\
2016 & 20.416 & 5.363 \\
2017 & 23.522 & 6.395 \\
2018 & 28.501 & 8.021 \\
\hline Sumber: Badan Pusat Statistik, diolah 2019
\end{tabular}

Meskipun indonesia sebagai produsen kelapa terbesar dan data ekspor komoditi sabut kelapa terus meningkat, pangsa pasar masih dikuasai oleh india dengan mengekspor 560.269 Ton dengan nilai 170.955.573 US\$ sedangkan indonesia hanya mampu mengekspor dengan volume 28.501 Ton dan nilai 8.021.000 US\$.

Usaha pengolahan sabut kelapa yang mengubah bentuk dari produk primer menjadi produk baru akan mendukung meningkatnya nilai ekonomi terhadap sabut kelapa yang selama ini belum dimanfaatkan dengan baik.

Sulawesi Utara merupakan daerah yang memiliki potensi dalam meningkatkan nilai ekspor produk sabut kelapa dan turunannya. Menurut Dirjen Perkebunan, Sulawesi utara pada tahun 2017 memiliki luas perkebunan kelapa sebesar 265.733 Ha dengan produksi sebesar 260.209 Ton, jadi ada sebesar 91.073
Ton Sabut kelapa yang di hasilkan. Data ekspor komoditi sabut kelapa di Selawesi utara terjadi peningkatan volume setiap tahunnya dan semuanya di sumbangkan oleh industry pengolahan dapat dilihat pada Tabel 2.

Tabel 2. Sata Ekspor Produk Turunan Sabut Kelapa Sulawesi Utara 2015 hingga 2018.

\begin{tabular}{lcc}
\hline & \multicolumn{2}{c}{ Sulawesi utara } \\
\cline { 2 - 3 } Tahun & Volume & Nilai (US\$) \\
\hline 2015 & 94.188 & $19.785,14$ \\
2016 & 849.574 & $231.237,38$ \\
2017 & 1.021 .260 & $344.365,11$ \\
2018 & 1.533 .215 & $462.048,71$ \\
\hline Total & $\mathbf{3 . 4 9 8 . 2 3 7}$ & $\mathbf{1 . 0 5 7 . 4 3 6 , 3 4}$ \\
\hline Sumber : Dinas Perindustrian dan Perdagangan Kota bitung
\end{tabular}

PT. Berkat Abadi Korindo Kota Bitung adalah salah satu perusahaan yang mengembangkan sabut kelapa menjadi "Fish Net" yang ada di Sulawesi utara, Industri ini mulai berproduksi sejak tahun 2016 hingga 2018 telah memproduksi "Fish Net" sebanyak $406.697 \mathrm{Kg}$ dengan nilai mencapai 456.960 US\$ tetapi perusahaan belum pernah menghitung tentang nilai tambah dari produk Fish Net. Untuk itu perlu dilakukan perhitungan nilai tambah sehingga bisa di ketahui berapa nilai tambah sabut kelapa yang di ubah bentuk menjadi produk "Fish Net" pada usaha pengolahan sabut kelapa di PT. Berkat Abadi Korindo.

\section{Nilai Tambah}

Komoditi pertanian bahan mentah dan muda rusak. Sehingga perlu langsung dikonsumsi atau diolah terlebih dahulu. Proses pengolahan dapat meningkatkan guna bentuk komoditikomoditi pertanian. Industri pengolahan hasil pertanian dapat meningkatkan nilai pada komoditi-komoditi pertanian. Peningkatan nilai pada komoditi pertanian membutuhkan biayabiaya pengolahan. Salah satu konsep yang sering digunakan untuk membahas pengolahan komoditi pertanian adalah nilai tambah (Sudiono dalam Karo, 2016). Konsep nilai tambah adalah suatu pengembangan nilai yang terjadi karena adanya input fungsional seperti perlakuan dan jasa yang menyebabkan bertambahnya kegunaan dan nilai komoditas selama mengikuti arus komoditas pertanian (Harjanto dalam Husain 2018). Input fungsional dapat berupa proses mengubah bentuk (From utility), menyimpan (Time utility), maupun melalui proses pemindahan tempat dan kepemilikan. 


\section{Agroindustri Sabut Kelapa}

Tanaman Kelapa banyak di gunakan dalam industry pangan maupun non pangan karena banyak produk yang di hasilkan dari tanaman kelapa. Kelapa dapat dikelompokan menjadi tiga sumber utama penghasil produk pangan dan non pangan. Ketiga sumber tersebut adalah (1) buah, (2) batang dan (3) lidi. Produk turunan dari pohon kelapa yang menghasilkan produk non pangan di antaranya batang, lidi, tempurung dan sabut.

Sabut kelapa adalah bagian dari buah kelapa yang dapat digunakan sebagai bahan baku untuk menghasilkan produk non pangan. Sabut kelapa merupakan komponen hasil dengan presentasi terbesar dari komponen buah kelapa yaitu $35 \%$, daging $28 \%$, air $25 \%$ dan tempurung 12\%. (Balitbang Deptan, 2005).

\section{Rumusan Masalah}

Adapun rumusan masalah dari penelitian ini adalah Berapa Nilai Tambah Sabut kelapa pada industri pengolahan PT. Berkat Abadi Korindo Kota Bitung?

\section{Tujuan Penelitian}

Penelitian ini bertujuan Untuk mengetahui Nilai Tambah Sabut kelapa pada industri pengolahan PT. Berkat Abadi Korindo Kota Bitung.

\section{Manfaat Penelitian}

Adapun manfaat dari penelitian ini nantinya yaitu:

1. Bagi penulis

a. Untuk memenuhi salah satu syarat untuk menyelesaikan study pada Universitas Sam ratulangi Fakultas PertanianJurusan Sosial Ekonomi Program Study Agribisnis.

b. Menerapkan Ilmu - ilmu yang di pelajari selama perkuliahan

2. Bagi pihak industri PT. Berkat Abadi Korindo diharapkan penelitian inni dapat memberikan informasi dalam pengembangan usaha.

3. Bagi pihak lain, diharapkan dapat menjadi informasi, serta dapat digunakan dalam penerapan konsep dan teori - teori pada penelitian di bidang yang sama.

\section{METODE PENELITIAN}

\section{Waktu dan Tempat Penelitian}

Penelitian ini dilaksanakan di PT Berkat Abadi Korindo Kota Bitung pada bulan Januari hingga Maret 2020. Penentuan lokasi dilakukan secara sengaja (purposive) dengan pertimbangan bahwa PT. Berkat Abadi Korindo merupakan satu - satunya perusahaan yang mengolah sabut kelapa menjadi produk "Fish Net" yang ada di Sulawesi utara.

\section{Metode Pengumpulan Data}

Jenis data yang digunakan dalam penelitian ini adalah data primer. Data primer diperoleh melalui wawancara secara langsung dengan pemilik perusahaan menggunakan list kebutuhan data yang telah dipersiapkan serta pengamatan langsung tentang keadaan di lapangan selama periode analisis. data primer yang dibutuhkan adalah data bahan baku (sabut kelapa), data hasil produksi ("Fish Net"), proses pengolahan serta data sumbangan input lain.

Teknik pengumpulan data yang di gunakan dalam penelitian ini adalah sebgai berikut:

1) Observasi

Teknik Obsevasi adalah teknik pengumpulan data yang dilakukan dengan mengadakan pengamatan langsung terhadap objek yang akan diteliti sehingga di dapatkan gambaran yang jelas mengenai objek yang akan diteliti tersebut.

2) Wawancara

Teknik wawancara merupakan teknik pengummpuan data yang dilakukan dengan Tanya jawab tatap muka antara pewancara dengan responden berdasaran daftar data yang diperlukan yang telah dipersiapkan seblumya.

3) Pencatatan

Teknik pencatatan merupakan teknik pengumpuan data yang dilakukan dengan cara mencatat hasil wawancara pada daftar data yang diperlukan. 


\section{Konsep Pengukuran Variabel \\ Variabel yang diukur dalam penelitian ini}

adalah:

1. Input adalah total sabut kelapa yang digunakan dalam produksi diukur dalam satuan kilogram (Kg/tiga bulan).

2. Output adalah hasil dari proses produksi yaitu berupa "Fish Net" diukur dalam jumlah satuan kilogram (kg/tiga bulan).

3. Pengolahan adalah suatu kesatuan kegiatan yang dilakukan untuk mengolah bahan baku menjadi produk yang bernilai tambah. Pengelohan "Fish Net" adalah suatu kesatuan kegiatan yang dilakukan untuk mengolah sabut kelapa menjadi "Fish Net".

4. Harga Input adalah harga sabut kelapa yang diterima oleh pelaku agroindustri dari hasil pembelian yang diukur dalam satuan rupiah $(\mathrm{Rp} / \mathrm{Kg})$.

5. Harga produk (Output) adalah harga "Fish Net" yang diterima oleh pengusaha agroindustri dan diukur dalam satuan rupiah $(\mathrm{Rp} / \mathrm{Kg})$.

6. Faktor konversi adalah banyaknya jumlah Output yang dapat dihasilkan dalam satu satuan input.

7. Faktor konversi pada industri dengan sabut kelapa menjadi "Fish Net" adalah perbandingan antara produk "Fish Net" yang dihasilkan dengan penggunaan sabut kelapa dalam perhitungan nilai tambah.

8. Nilai tambah adalah selisi antara nilai Output "Fish Net" dengan harga bahan baku utama sabut kelapa dan sumbangan Input lain yang diukur dalam satuan rupiah.

\section{Metode Analisis Data}

Data hasil penelitian di analisis secara deskripsi kuantitatif. Deskriptif kuantitatif bertujuan untuk menganalisis data dengan cara mendeskripsikan atau menggambarkan data yang telah terkumpul sebagaimana adanya.

Analisis yang digunakan dalam penelitian ini adalah menggunakan analisis nilai tambah pengolahan sabut kelapa menjadi "Fish Net". Besarnya nilai tambah suatu barang atau produk dapat dihitung dengan rumus sebagai berikut (Hayami dalam Husain, 2018).

Nilai tambah = Nilai Output - Harga Output - Sumbangan input lain

Keterangan :

- Nilai Output adalah hasil yang didapatkan dari perkalian antara factor konversi dan harga output dalam satu satuan produksi.
Nilai output = Faktor konversi $x$ Harga Produk "Fish Net" $(\mathrm{Rp} / \mathrm{Kg})$

- Sumbangan input lain adalah bahan - bahan penunjang yang digunakan dalam pembuatan produk "Fish Net" yang diterima pengusaha dan diukur dalam satuan rupiah $(\mathrm{Rp} / \mathrm{Kg})$.

- Faktor konversi adalah banyaknya jumlah output yang dihasilkan dalam satu satuan input. Factor konversi pada industri pengolahan produk Fishnet yang dihasilkan dengan penggunaan sabut kelapa.

$$
\text { Faktor konversi }=\frac{\text { Jumlah Fishnet (Output) }}{\text { Jumlah Sabut kalap (Input) }}
$$

- Output adalah total produksi produk Fishnet yang dihasilkan

- Input adalah bahan baku berupa sabut kelapa yang digunakan dalam proses produksi.

Kriteria Nilai tambah adalah:

(a) Jika NT >0, Berarti industri pengolahan sabut kelapa menjadi Fishnet memberikan nilai tambah (Positif).

(b) Jika NT < 0, Berarti industri pengolahan sabut kelapa menjadi Fishnet tidak emberikan nilai tambah (Negatif).

\section{HASIL DAN PEMBAHASAN}

\section{Gambaran Umum PT. Berkat Abadi Korindo}

PT. Berkat Abadi Korindo merupakan salah satu usaha pengolahan berbahan sabut kelapa di Sulawesi Utara. Industri ini terletak di Kecamatan Matuari Kota Bitung. Industri ini didirikan pada tahun 2014 dan mulai beroprasi pada tahun 2016 oleh Bapak Young Jung Kang selaku pemilik agroindustri. Awal pelaku agroindustri mendirikan pabrik di Kota Bitung dengan melihat potensi untuk mengembangkan industri pengolahan sabut kelapa karena bahan baku yang berlimpah, tenaga kerja yang memadai dan akses ke pelabuhan untuk ekspor produk yang dekat. Agroindustri pengolahan ini sudah memiliki badan hukum yaitu PT dengan nama PT Berkat Abadi Korindo. Khususnya pada pengolahan sabut kelapa yang awalnya di anggap limbah. 
Bangunan PT Berkat abadi Korindo mencakup tempat bahan baku, tempat penggilingan, tempat pengayakan, tempat pemintalan, tempat penyimpanan produk serta kantor yang dapat di lihat pada Gambar 1 .

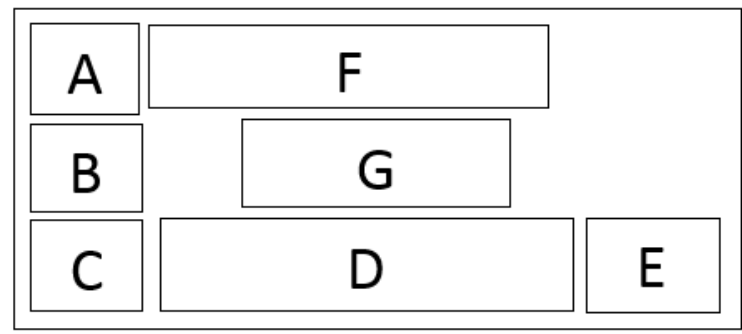

Gambar 1. Denah agroindustry pengolahan PT. Berkat abadi Korindo

Keterangan :
A. Tempat bahan baku
B. Tempat penggilingan dan penghalusan
C. Tempat Pengayakan
D. Tempat Pemintalan
E. Tempat penyimpanan produk
F. Kantor
G. Lahan penjemuran

\section{Deskripsi produk "Fishnet"}

Produk pengolahan yang dihasilkan oleh PT Berkat abadi Korindo adalah produk "Fish Net" yang diolah dari sabut kelapa. Produk "Fish Net" merupakan tali sabut kelapa yang di jahit menjadi jaring dengan diameter 1 x 2 meter dengan panjang tali sabut 200 meter yang di ekspor ke korea untuk dijadikan tempat ternak ikan. Proses pengolahan produk Fishnet tergolong modern. Pengolahan "Fish Net" menggunakan mesin dari awal penghancuran bahan baku sampai pemintalan dan press.

\section{Perhitungan Nilai Tambah}

Nilai tambah adalah pertambahan nilai dari suatu produk karena mengalami proses pengolahan, pengangkutan dan penyimpanan. Nilai tambah terjadi dalam proses pengolahan merupakan selisih dari nilai produk dengan nilai input dan nilai input lainnya. Nilai output adalah total penerimaan produk " $F$ ish Net". Nilai input adalah biaya bahan baku dan nilai input lainnya adalah biaya bahan penolong. Hasil perhitungan Nilai tambah dapat dilihat pada tabel berikut.

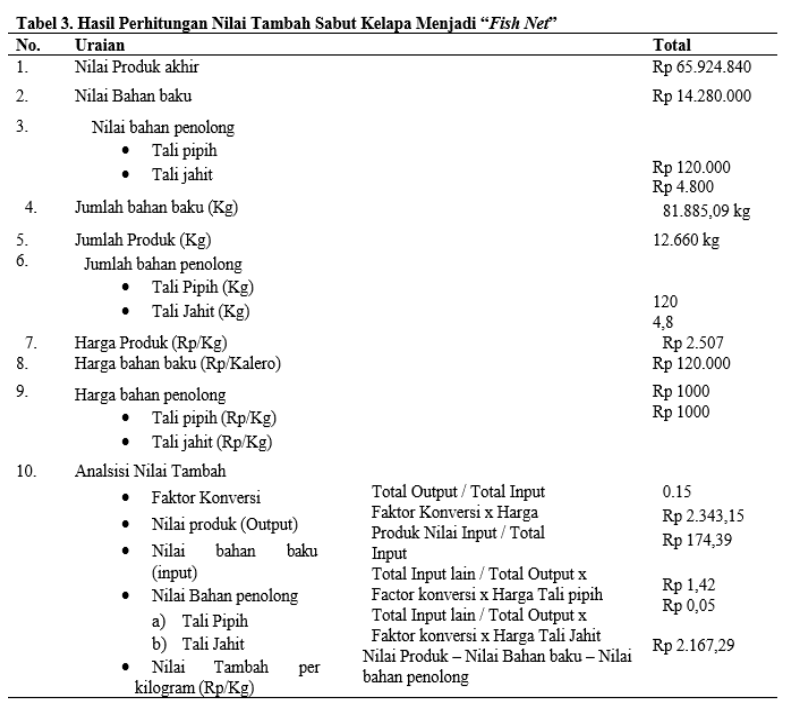

Tabel 3 di atas menunjukkan bahwa keluaran berupa "Fish Net" di produksi sebanyak $12.660 \mathrm{~kg}$ tersebut membutuhkan $81.885,09 \mathrm{~kg}$ sabut kelapa. Factor konversi sebesar 0.15 menunjukan bahwa setiap $1 \mathrm{~kg}$ sabut kelapa dapat menghasilkan $0.16 \mathrm{~kg}$ produk "Fish Net".

Pada kondisi harga produk "Fish Net" ratarata $\mathrm{Rp} 2.507,9 / \mathrm{Kg}$ diperoleh harga input bahan baku yang berupa sabut kelapa sebesar $\mathrm{Rp}$ $174.39 / \mathrm{Kg}$ sabut. Biaya lain yang harus dikeluarkan untuk bahan pendukung lainnya seperti tali pipih dan tali jahit dengan harga $\mathrm{Rp} 1.47$ / Kg. dengan demikian pengolahan $1 \mathrm{Kg}$ sabut kelapa dengan harga $\mathrm{Rp} 174.39$ kemudian ditambah dengan bahan penolong yang membutuhkan biaya sebesar $\mathrm{Rp} 1.47$ dapat menghasilkan $0,16 \mathrm{Kg}$ produk "Fish Net" dengan harga Rp 2.343,15 jadi nilai tambah produk "Fish Net" adalah selisi dari nilai produk "Fish Net" dengan nilai sabut kelapa dan input lain berupa tali pipih dan tali jahit sebesar Rp 2.167,29 atau nilai tambah lebih dari nol (positif). Berarti pengolahan sabut kelapa yang merubah bentuk menjadi produk "Fish Net" memberikan nilai tambah.

\section{KESIMPULAN DAN SARAN}

\section{Kesimpulan}

Berdasarkan hasil penelitian dan pembahasan Nilai tambah sabut kelapa yang mengolah sabut kelapa menjadi "Fish Net" di PT Berkat Abadi kodrindo Kecamatan Matuari kota Bitung memberikan nilai tambah lebih dari 0 atau sebesar Rp 2.331,14 dari setiap $1 \mathrm{~kg}$ sabut kelapa menjadi $0,16 \mathrm{~kg}$ "Fish Net". 


\section{Saran}

Berdasarkan hasil penelitian saran yang dapat di berikan adalah untuk mempertahankan kualitas penggunaan bahan baku pada produk "Fish Net". Serta mengembagkan pengolahan produk turunan sabut kelapa selain "Fish Net" dari bahan baku yang tidak terpakai dalam pengolahan sehingga nilai tambah dari sabut kelapa akan bertambah.

\section{DAFTAR PUSTAKA}

Buletin Statistic Perdagangan Luar Negeri Ekspor Komoditi HS, Desember 2015 2018 Badan Penelitian Dan Pengembangan Pertanian, Depertemen Pertanian. Juli 2005.
Husain AH. 2018. Analisis Kinerja Dan Nilai Tambah Agroindustry Sagu Aren Di Lampung Selatan. Fakultas Pertanian, Universitas Lampung Bandar Lampung. Karo. 2016. Analisis Nilai Tambah Dan Pendapatan Mie Jagung Pada Kelompok Wanita Tani Bunga Anggrek Kecamatan Saronggi Kabupaten Sumenep. Fakultas Pertanian, Universitas Jember. 